\title{
Effects of mixed formulation of tamoxifen and blue honeysuckle on the pharmacokinetics profiles of tamoxifen after single oral administration
}

\author{
Jin-Ryul Hu${ }^{1 *}$, Tae-Woo Jang ${ }^{1^{*}}$, Su-Jin Kang ${ }^{1,2^{*}}$, Sae-Kwang Ku ${ }^{1,2}$, \\ Seong-Hun Choi ${ }^{1 \dagger}$, Young-Joon $\mathrm{Lee}^{3 \dagger}$ \\ ${ }^{1}$ Department of Anatomy and Histology, College of Korean Medicine, Daegu Haany University, \\ Gyeongsan 38610, Republic of Korea \\ ${ }^{2}$ The Medical Research center for Herbal Convergence on Liver Disease, Daegu Haany University, \\ Gyeongsan 38610, Republic of Korea. \\ ${ }^{3}$ Department of Preventive Medicine, College of Korean Medicine, Daegu Haany University, \\ Gyeongsan 38610, Republic of Korea
}

Objectives: Here, we investigated the effects of concentrated and lyophilized powders Blue honeysuckle (BH) on the PK of tamoxifen, to establish the pharmacokinetics (PK) profiles as one of essential process in new drug development. Methods: After single oral treatment of $0.4 \mathrm{mg} / \mathrm{ml}$ of tamoxifen or tamoxifen 0.4 with $\mathrm{BH} 40,20 \mathrm{and} 10 \mathrm{mg} / \mathrm{ml}$, the plasma were collected at $0.5 \mathrm{hr}$ before administration, $0.5,1,2,3,4,6,8$ and $24 \mathrm{hr}$ after end of single or mixed formula treatment. Plasma concentrations of tamoxifen were analyzed using LC-MS/MS methods. Tmax, Cmax, AUC, $\mathrm{t} 1 / 2$ and MRTinf were analyzed using noncompartmental PK data analyzer programs.

Results: Tamoxifen and $\mathrm{BH} 40 \mathrm{mg} / \mathrm{ml}$ did not induce any significant change on the plasma tamoxifen concentrations, while significant decreases were observed in tamoxifen and $\mathrm{BH} 10 \mathrm{mg} / \mathrm{ml}$ from 2 to $8 \mathrm{hr}$ as compared with tamoxifen only, respectively. Furthermore, significant increases of Tmax in tamoxifen and BH $40 \mathrm{mg} / \mathrm{ml}$, significant decreases of Cmax in tamoxifen and BH $20 \mathrm{mg} / \mathrm{ml}$, significant decreases of AUC0-t, AUC0-inf and MRTinf in tamoxifen and $\mathrm{BH} 10 \mathrm{mg} / \mathrm{ml}$ were demonstrated as compared with tamoxifen only.

Conclusion: Taken together, tamoxifen and BH $10 \mathrm{mg} / \mathrm{ml}$ induced significant decrease of the oral bioavailability of tamoxifen, while tamoxifen and $\mathrm{BH} 40$ or $20 \mathrm{mg} / \mathrm{ml}$ did not critically influenced, suggesting formulated $\mathrm{BH}$ concentration-independencies. It, therefore, seems to be needed that pharmacokinetic study after repeated administration should be tested to conclude the effects of $\mathrm{BH}$ on the pharmacokinetics of tamoxifen.

Key Words : Blue honeysuckle, Tamoxifen, Mixed formulation, Pharmacokinetics, Drug-drug interactions, Rat

\author{
- Received : 22 May 2019 \\ - Revised : 15 November 2019 \\ - Accepted : 18 November 2019 \\ - Hu JR, Jang TW and Kang SJ contricontributed equally to this work \\ - Correspondence to : Seong-Hun Choi \\ Department of Histology and Anatomy, College of Korean Medicine, Daegu Haany University \\ 1, Hannydaero, Gyeongsan, Gyeongsangbuk-Do, 38610, Republic of Korea. \\ Tel : +82-53-819-1872, Fax : +82-53-819-1576, E-mail : ck0190@hanmail.net \\ - Correspondence to : Young-Joon Lee \\ Department of Preventive Medicine, College of Korean Medicine, Daegu Haany University, \\ 1, Hannydaero, Gyeongsan, Gyeongsangbuk-Do, 38610, Republic of Korea. \\ Tel : +82-53-819-1296, Fax : +82-53-819-1576, E-mail : gksxntk@dhu.ac.kr
}




\section{Introduction}

Pharmacokintics (PK) is a branch of pharmacology dedicated to the determination of the fate of substances administered externally to a living organism. PK includes the study of the mechanisms of absorption and distribution of an administered drug, the rate at which a drug action begins and the duration of the effect, the chemical changes of the substance in the body ${ }^{1,2}$. PK of drugs in animals, especially rodents have been provided a valuable data for absorption, distribution, metabolism and elimination of drugs in vivo, directly related with their pharmacodynamics. Therefore, the PK profiles have been observed as one of essential process in new drug development including natural products ${ }^{1-4)}$. In addition, they also provided constantly reliable data on the possible potential drug-drug interactions, when drugs were co-administered ${ }^{2-4)}$.

Tamoxifen is a nonsteroidal estrogen agonist -antagonist antineoplastic agent has been used for breast cancer ${ }^{5)}$. It is the usual endocrine (anti-estrogen) therapy for hormone receptor -positive breast cancer in pre-menopausal women, and is also a standard in post-menopausal women although aromatase inhibitors are also frequently used in that setting ${ }^{6,7)}$. Tamoxifen causes cells to remain in the G0 and G1 phases of the cell cycle. Because it prevents (pre)cancerous cells from dividing but does not cause cell death, tamoxifen is cytostatic rather than cytocidal ${ }^{8,9}$. However, various side effects related to tamoxifen treatment also have been arise as bone loss in premenopausal women who continue to menstruate after adjuvant chemotherapy ${ }^{10)}$, endometrial changes, including cancer, are among tamoxifen's side effects ${ }^{11}$, increased risk of thromboembolism ${ }^{12)}$, cause of fatty liver ${ }^{13)}$, reduced cognition ${ }^{14)}$, semantic memory scores $^{15)}$ and libido ${ }^{16,17)}$, and premature growth plate fusion ${ }^{18)}$. Tamoxifen also depress the immune response ${ }^{19,20)}$, and it also known that hypersensitivity to tamoxifen or any ingredient in the formulation $^{21,22)}$.

Tamoxifen is contraindicated, when used in women with ductal carcinoma in situ and women at high risk for breast cancer, concurrent anticoagulant therapy with a warfarin derivative ${ }^{23)}$, and be used with caution in patients with leukopenia or thrombocytopenia ${ }^{24)}$ and pregnant ${ }^{25,26)}$. Hot flashes, vaginal discharge, menstrual irregularities and weight loss are common side effects related with tamoxifen treatment ${ }^{25,27)}$.

As results of combination therapies with other drugs to improve the side effects of tamoxifen or to achieve synergic effects, various drug-drug interactions of tamoxifen have been evaluated; Because tamoxifen was metabolized by a substrate of CYP3A, 2C9, 2D6 $6^{28)}$, it interacted with various drugs, namely, combinations containing any of the following medications, depending on the amount present, may also interact with aminoglutethimide - decreased plasma tamoxifen and N-desmethyltamoxifen concentrations $^{29)}$, anticoagulants - enhanced warfarin effects $^{30,31)}$, bromocriptine - increased plasma tamoxifen and $\mathrm{N}$-desmethyltamoxifen concentrations ${ }^{32}$, letrozole - decreased plasma letrozole concentrations ${ }^{33)}$, medroxyprogesterone - decreased plasma N-desmethyltamoxifen concentrations but did not reduce plasma tamoxifen concentrations ${ }^{34)}$, phenobarbital decreased plasma tamoxifen concentrations ${ }^{35}$, rifampin - decreased plasma tamoxifen and N-desmethyltamoxifen concentrations ${ }^{36)}$, and cyclosporine, erythromycin, diltiazem, erythromycin and nifedipine - competitively inhibited formation of N-desmethyltamoxifen in vitro ${ }^{37-39)}$, respectively. 
However, interactions with herbal products have not been established except for some restricted natural compounds ${ }^{30,31)}$.

Until now, we have observed the possible interactions with Korean traditional polyherbal formulas; oral co-administration of Jaeumkanghwa-tang, a traditional yin-tonifying herbal medicine used for various oriental obstetrical and gynecological fields within $5 \mathrm{~min}$ did not critically influenced on the pharmacokinetics profiles of tamoxifen after single $^{40)}$ and repeated ${ }^{41)}$ co-administration at dosage levels of $50 \mathrm{mg} / \mathrm{kg}$ in tamoxifen and 100 $\mathrm{mg} / \mathrm{kg}$ in Jaeumkanghwa-tang, respectively. It was also demonstrated that single co-administration of Gamiondam-tang within $5 \mathrm{~min}$ and with 2.5 hr-intervals critically influenced on the oral bioavailability of tamoxifen through variable influences on the absorption and excretion of tamoxifen at dosage levels of GMODT $100 \mathrm{mg} / \mathrm{kg}$ and tamoxifen $50 \mathrm{mg} / \mathrm{kg}$, can be influenced on the toxicity or pharmacodynamic of tamoxifen in our previous studies ${ }^{42,43)}$.

Blue honeysuckle (Berries of Lonicera caerulea L., Caprifoliaceae) is a traditional shrub used in folk medicine in northern Russia, China, and Japan, but its fruits are little known as edible berries in North America and Europe, and also in Korea $^{44)}$. The berries are a rich source of ascorbic acid and phenolic components, particularly anthocyanins, flavonoids and low molecular weight phenolic acids ${ }^{44)}$. These compounds have been reported to have multiple biological activities including strong antioxidant activity ${ }^{44}$. Recently, orally administered blue honeysuckle was reported to protect mice against ionizing radiation ${ }^{45}$, ameliorates abnormal lipid and glucose metabolism in rats ${ }^{46)}$, hepatoprotective effects ${ }^{47)}$, anti-inflammatory effects ${ }^{48)}$. Especially blue honeysuckle extracts have been showed the strongest antioxidant potent among 12 types of colored berries ${ }^{49)}$, and phenolic rich extract of $\mathrm{BH}$ has been shown to possess anti-inflammatory and wound-healing effects in vitro and in vivo ${ }^{48)}$ and skin protective effects to ultraviolet-induced damages $^{50)}$ with less toxicity ${ }^{51)}$.

In the present study, the effects of $\mathrm{BH}$ on the pharmacokinetics of tamoxifen were examined in rats after mixed formulation as tamoxifen 0.4 and $\mathrm{BH} 40,20$ and $10 \mathrm{mg} / \mathrm{ml}$ concentrations. After single oral treatment of $4 \mathrm{mg} / \mathrm{kg}$ of tamoxifen single formula or tamoxifen 0.4 with $\mathrm{BH} 40,20$ and $10 \mathrm{mg} / \mathrm{ml}$ concentration mixed formulas, the plasma were collected at $30 \mathrm{~min}$ before administration, $30 \mathrm{~min}, 1,2,3,4,6,8$ and $24 \mathrm{hr}$ after end of single or mixed formula treatment. Plasma concentrations of tamoxifen were analyzed using LC-MS/MS methods. PK parameters of tamoxifen (Tmax, Cmax, AUC, $\mathrm{t}_{1 / 2}$ and $\mathrm{MRT}_{\mathrm{inf}}$ ) were analysis as compared with tamoxifen single formula administered rats.

\section{Materials \& methods}

\section{Animals and husbandry}

A total of fifty-three male SPF/VAF Outbred Crl:CD [SD] rats (OrientBio, Seungnam, Korea) were used after acclimatization for 15 days. Animals were allocated five per polycarbonate cage in a temperature $\left(20-25^{\circ} \mathrm{C}\right)$ and humidity (40-45\%) controlled room. Light : dark cycle was $12 \mathrm{hr}: 12 \mathrm{hr}$ and feed (Samyang, Korea) and water were supplied free to access. After 15 days of acclimatization, four groups of 5 rats each were selected based on the body weights, and used further experiments, in the present study. All animals were marked by picric acid, and overnight 
fasted (about $18 \mathrm{hr}$; water was not restricted) before treatment, and further fasted during $3 \mathrm{hr}$ after end of treatment. Animal experiments were conducted according to the national regulations of the usage and welfare of laboratory animals, and approved by the Institutional Animal Care and Use Committee in Daegu Haany University (Gyeongsan, Gyeongbuk, Korea) [Approval Approval No DHU2014-081].

\section{Test articles}

Deep purple colored solution of concentrated blue honeysuckle, about 63 brix, were supplied by H\&K Bioscience Co., Ltd. (Seoul, Korea) and used as same as our previous single oral dose toxicity test $^{51)}$ in this experiment. The brief process for making $\mathrm{BH}$ was as follows. $200 \mathrm{~g}$ of 63 brix concentrated blue honeysuckle solutions supplied by H\&K Bioscience were diluted into 25 brix using distilled water, and then completely lyophilized by programmable freeze dryer (Operon FDB-5503, Kimpo, Korea). Total 124.40 g (yield $=62.2 \%$ ) of $\mathrm{BH}$ were acquired. At proximate analysis of $\mathrm{BH}$ by Association of Official Analytical Chemists (AOAC) ${ }^{52)}$ methods, BHcL contains energy $380 \mathrm{kcal} / 100 \mathrm{ml}$, carbohydrate 93 $\mathrm{g} / 100 \mathrm{ml}$, sugar $41 \mathrm{~g} / 100 \mathrm{ml}$, protein $2 \mathrm{~g} / 100 \mathrm{ml}$, sodium $20 \mathrm{mg} / 100 \mathrm{ml}$, but it did not contains total lipids $(0 \mathrm{mg} / 100 \mathrm{ml})$, saturated lipids $(0 \mathrm{mg} / 100$ $\mathrm{ml})$, trans-fat $(0 \mathrm{mg} / 100 \mathrm{ml})$, cholesterol $(0 \mathrm{mg} / 100$ $\mathrm{ml})$, respectively. In addition, phytochemical analysis of $\mathrm{BH}$ reveals that it contains $4.54 \pm$ $0.09 \%$ of betaine by high performance liquid chromatography (HPLC), $210.63 \pm 23.65 \mathrm{mg}$ gallic acid equivalents (GAE)/g of total phenols by Folin-Ciocalteu colorimetric method ${ }^{53)}, 159.30$ $\pm 12.51 \mathrm{mg}$ catechin equivalents $(\mathrm{CE}) / \mathrm{g}$ of total flavonoids by a modified colorimetric method ${ }^{54)}$ and $133.57 \pm 4.06 \mathrm{mg}$ malvidin-3-O-glucoside equivalents (M3GE)/g of total antocyanins by a modified $\mathrm{pH}$ differential method ${ }^{55)}$, respectively. In addition, white crystalline powders of tamoxifen (Kunshan SanYou Pharmaceutical Material Co., Ltd., Suzhou, China) was used as control drug as listed follows. Tamoxifen and $\mathrm{BH}$ were stored in a refrigerator at $4^{\circ} \mathrm{C}$ and $-20{ }^{\circ} \mathrm{C}$ to protect from light and degeneration until use. Both drugs are well dissolved (up to $40 \mathrm{mg} / \mathrm{ml}$ solutions in $\mathrm{BH}$ and upto $0.4 \mathrm{mg} / \mathrm{ml}$ solutions in tamoxifen) in distilled water as vehicle, respectively.

\section{Groupings, test article formulation and administration}

Four groups of 5 rats each were used in this study as follows. The dosages of tamoxifen 4 $\mathrm{mg} / \mathrm{kg}$ were selected, considering the clinical dosage in human and body surface of rats. Single formula of tamoxifen was prepared as dissolved in distilled water $(0.4 \mathrm{mg} / \mathrm{ml}$ concentration), and each mixed formula consisted of tamoxifen and $\mathrm{BH}$ was prepared by dissolved of approximate amounts of tamoxifen $(0.4 \mathrm{mg} / \mathrm{ml})$ and $\mathrm{BH}(40,20$ or 10 $\mathrm{mg} / \mathrm{ml}$ ) in distilled water. Tamoxifen single formula and all three types of mixed formula consisted of tamoxifen and $\mathrm{BH}$ were once orally administered, in a volume of $10 \mathrm{ml} / \mathrm{kg}$, respectively.

\section{Plasma collections}

All rats were anesthetized with 2 to $3 \%$ isoflurane (Hana Pharm. Co., Hwasung, Korea) in the mixture of $70 \% \mathrm{~N}_{2} \mathrm{O}$ and $28.5 \% \mathrm{O}_{2}$, and blood samples $(0.5 \mathrm{ml})$ were collected into $50 \mathrm{IU}$ heparinized $0.7 \mathrm{ml}$ Eppendorf tubes through the orbital plexus at $30 \mathrm{~min}$ before treatment (as a control), $30 \mathrm{~min}, 1,2,3,4,6,8$ and $24 \mathrm{hr}$ after 
end of single oral administration of tamoxifen single or mixed formula with three different dosages of $\mathrm{BH}$, respectively. Blood samples were immediately centrifuged for $10 \mathrm{~min}$ at $13,000 \mathrm{rpm}$ and about $0.3 \mathrm{ml}$ aliquots of plasma were stored in a $-150{ }^{\circ} \mathrm{C}$ deep freezer until analysis of tamoxifen.

\section{Sample preparation and calibrations}

Primary stock solution, $1.0 \mathrm{mg} / \mathrm{ml}$ of tamoxifen in 50\% acetonitrile (Sigma-Aldrich, St Louise, MO, USA) mixtures with distilled water and internal standard working solution, carbamazepine (Sigma-Aldrich, St Louise, MO, USA) $500 \mathrm{ng} / \mathrm{ml}$ in acetonitrile were prepared. Working standard solutions were prepared by dilution with acetonitrile. All standard solutions were stored at $-20^{\circ} \mathrm{C}$ in the dark when not in use, and calibrated the standard samples as $100 \mu$ l of blank plasma; working standard solutions and internal standard working solution were mixed with $100 \mu \mathrm{l}$ of acetonitrile. In addition, $100 \mu 1$ of sample plasma and internal standard working solution were mixed with $200 \mu$ of acetonitrile. The mixtures were mixed by vortex-mixing and centrifuged at 12,000 rpm for $10 \mathrm{~min}$ at $4^{\circ} \mathrm{C}$. Clear supernatants $(150 \mu$ 1) were directly transferred to injection vials and the aliquot $(5.0 \mu \mathrm{l})$ was injected into the LC-MS/MS system.

\section{LC-MS/MS conditions}

Concentrations of tamoxifen in the rat plasma samples were determined LC-MS/MS method. Chromatographic analysis was performed using an Agilent 1100 Series HPLC (Agilent Technologies, Santa Clara, CA, USA) equipped with on-line degasser, binary pump, autosampler and column compartment. Separation of the analyte from potentially interfering material was achieved at ambient temperature using Waters Symmetry $^{\mathrm{TM}}$ $\mathrm{C}_{18}(2.1 \times 50 \mathrm{~mm}, 3.5 \mu \mathrm{m})$ (Waters Corp., Milford, MA, USA) at column oven $30^{\circ} \mathrm{C}$. The mobile phase used for the chromatographic separation was composed of $50 \%$ distilled water $(0.1 \%$ formic acid) / 50\% acetonitrile and was delivered isocratically at a flow rate of $0.35 \mathrm{ml} / \mathrm{min}$. The column effluent was monitored using an API 2000 triple-quadruple mass-spectometric detector (Applied Biosystems, Foster City, CA, USA). The instrument was equipped with an electrospray interface in positive ion mode, and controlled by the Analyst version 1.4.1 software (Applied Biosystems, Foster City, CA, USA). Samples were introduced to the interface through a Turbo Ion Spray with the temperature set at $500^{\circ} \mathrm{C}$. A high positive voltage of $4.0 \mathrm{kV}$ was applied to the ion spray. Nitrogen was used as the nebulizer gas, curtain gas, and collision gas with the settings of 70,20 , and 7 , respectively. The multiple reaction monitoring (MRM) detection method was employed for the detection of tamoxifen; the transitions monitored were carbamazepine (IS): $\mathrm{m} / \mathrm{z} \quad 237>194$ (Retention time: $0.74 \mathrm{~min}$ ), tamoxifen: 372>178 (Retention time: $0.55 \mathrm{~min}$ ). Calibration curves of tamoxifen were linear over the ranges studied with $r^{2}>0.994$. The lower limit of quantification of the tamoxifen in the rat plasma was $0.5 \mathrm{ng} / \mathrm{ml}$.

\section{Pharmacokinetic analysis}

The plasma concentration data were analyzed using a noncompartmental method on commercial pharmacokinetics data analyzer programs (PK solutions2.0; Summit, Montrose, CO, USA) ${ }^{56}$. The elimination rate constant $\left(\mathrm{K}_{\mathrm{el}}\right)$ was calculated by the log-linear regression of tamoxifen concentration 
data during the elimination phase, and the terminal half-life $\left(\mathrm{t}_{1 / 2}\right)$ was calculated by $0.693 / \mathrm{K}_{\mathrm{el}}$. The peak concentration (Cmax) and time to reach the peak concentration (Tmax) of tamoxifen in the plasma were obtained by visual inspection of the data in the concentration-time curve. The area under the plasma concentration-time curve $\left(\mathrm{AUC}_{0-\mathrm{t}}\right)$ from time zero to the time of the last measured concentration $\left(\mathrm{C}_{\text {last }}\right)$ was calculated using the linear trapezoidal rule ${ }^{57)}$. The AUC zero to infinity $\left(\mathrm{AUC}_{0 \text {-inf }}\right)$ was obtained by adding $\mathrm{AUC}_{0-\mathrm{t}}$ and the extrapolated area was determined by $\mathrm{C}_{\text {last }} / \mathrm{K}_{\mathrm{el}}$. The mean residence time infinity $\left(\mathrm{MRT}_{\mathrm{inf}}\right)$ was calculated by dividing the first moment of $\operatorname{AUC}\left(\mathrm{AUMC}_{0 \text {-inf }}\right)$ by $\mathrm{AUC}_{0 \text {-inf. }}$

\section{Statistical analyses}

All the means are presented with their standard deviation (SD) of five rats (Mean $\pm \mathrm{SD}$ of five rat plasma tamoxifen concentrations). The pharmacokinetic parameters were compared using a non-parametric comparison test, Mann-Whitney U (MW) test, on the SPSS for Windows (Release 14.0K, SPSS Inc., Chicago, IL, USA). A p-value $<0.05$ was considered statistically significant. In addition, the percent-point changes between tamoxifen single formula treated rats and tamoxifen with $\mathrm{BH} 40,20$ or $10 \mathrm{mg} / \mathrm{ml}$ mixed formula administered rats were calculated to help the understanding of the effects after mix formulations, according to our previous study ${ }^{58)}$ : Percentage-point changes as compared with tamoxifen $0.4 \mathrm{mg} / \mathrm{ml}$ single formula treated mice $(\%)=[(($ Data of mixed formula administrated rats - data of tamoxifen single formula treated rats)/Data of tamoxifen single formula treated rats) $\times 100$ ].

\section{Results}

\section{Changes on the plasma concentrations of tamoxifen}

Tamoxifen was detected from $30 \mathrm{~min}$ to $24 \mathrm{hr}$ after end of administration in tamoxifen single formula and all three different concentrations of mixed formulas with $\mathrm{BH}$ administered rats, respectively. Although single oral administration of mixed formulas consisted of tamoxifen and $\mathrm{BH} 40$ $\mathrm{mg} / \mathrm{ml}$ did not induced any significant changed on the plasma tamoxifen concentrations, but significant $(p<0.01$ or $p<0.05)$ decreases of plasma tamoxifen concentrations were demonstrated in tamoxifen and $\mathrm{BH} 20 \mathrm{mg} / \mathrm{ml}$ mixed formula treated rats at 1,2 and $6 \mathrm{hr}$ after administration, and also in BH $10 \mathrm{mg} / \mathrm{ml}$ mixed formula treated rats from 2 to $8 \mathrm{hr}$ after end of treatment as compared with tamoxifen $0.4 \mathrm{mg} / \mathrm{ml}$ single formula treated rats, in the current result (Fig 1).

\section{Changes on the Tmax of tamoxifen}

The Tmax of tamoxifen were significantly $(p<0.05)$ increased as $172.73 \%$ points in tamoxifen and $\mathrm{BH} 40 \mathrm{mg} / \mathrm{ml}$ mixed formula treated rats $(3.00 \pm 1.00 \mathrm{hr})$ as compared with tamoxifen single formula treated rats $(1.10 \pm 0.55 \mathrm{hr})$. The Tmax of tamoxifen were non-significantly changed as 27.27 and $9.09 \%$ points in tamoxifen and $\mathrm{BH} 20$ or 10 $\mathrm{mg} / \mathrm{ml}$ mixed formula treated rats as compared with tamoxifen single formula treated rats; they were detected as $1.40 \pm 0.89$ and $1.20 \pm 0.45 \mathrm{hr}$ in tamoxifen and BH 20 or $10 \mathrm{mg} / \mathrm{ml}$ mixed formula treated rats, respectively (Table 1 ).

\subsection{Changes on the Cmax of tamoxifen}

The Cmax of tamoxifen were significantly 


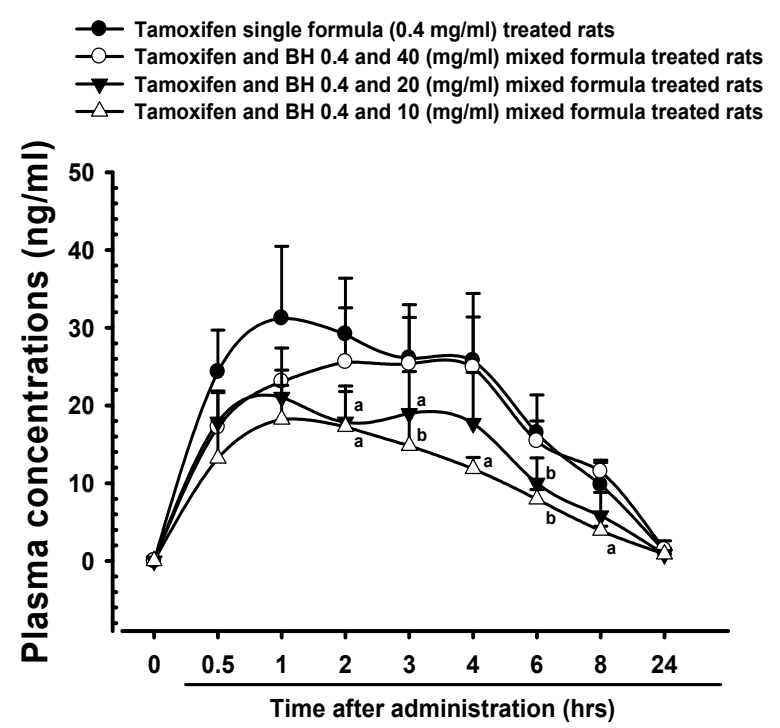

Fig. 1. Plasma concentrations of tamoxifen after single oral administration of tamoxifen single or mixed formulas with BH 40, 20 or $10 \mathrm{mg} / \mathrm{ml}$ in male rats. Values are expressed as mean \pm S.D. of five rats $(\mathrm{ng} / \mathrm{ml})$. BH = Blue honeysuckle (fruit parts of Lonicera caerulea L., Caprifoliaceae) concentrated and lyophilized powder. ${ }^{a} p<0.01$ and ${ }^{\mathrm{b}} \mathrm{p}\langle 0.05$ as compared with tamoxifen single formula administered rats.

$(\mathrm{p}<0.05)$ decreased as $-32.90 \%$ points in tamoxifen and $\mathrm{BH} 20 \mathrm{mg} / \mathrm{ml}$ mixed formula treated rats $(21.46 \pm 4.01 \mathrm{ng} / \mathrm{ml})$ as compared with tamoxifen single formula treated rats $(31.98 \pm 8.98 \mathrm{ng} / \mathrm{ml})$. The Cmax of tamoxifen were non-significantly changed as -15.13 and $-33.77 \%$ points in tamoxifen and $\mathrm{BH} 40$ or $10 \mathrm{mg} / \mathrm{ml}$ mixed formula treated rats as compared with tamoxifen single formula treated rats; they were detected as $27.14 \pm 7.24$ and $21.18 \pm 7.61 \mathrm{ng} / \mathrm{ml}$ in tamoxifen and $\mathrm{BH} 20$ or $10 \mathrm{mg} / \mathrm{ml}$ mixed formula treated rats, respectively (Table 1).

Table 1. Pharmacokinetic parameters of tamoxifen after single oral administration of tamoxifen single or mixed formulas with $\mathrm{BH} 40,20$ or $10 \mathrm{mg} / \mathrm{ml}$ in male rats.

\begin{tabular}{lcccc}
\hline \multirow{2}{*}{$\begin{array}{l}\text { Treatment } \\
\text { PK Parameters }\end{array}$} & \multicolumn{2}{c}{$\begin{array}{c}\text { Tamoxifen single } \\
\text { formula }\end{array}$} & \multicolumn{3}{c}{ Tamoxifen mixed formulas with BH } \\
\cline { 2 - 5 } & $0.4 \mathrm{mg} / \mathrm{ml}$ & $3.00 \pm 1.00^{\mathrm{b}}$ & $1.40 \pm 0.89$ & $10 \mathrm{mg} / \mathrm{ml}$ \\
\hline Tmax $(\mathrm{hr})$ & $1.10 \pm 0.55$ & $27.14 \pm 7.24$ & $21.46 \pm 4.01^{\mathrm{b}}$ & $21.18 \pm 7.61$ \\
$\mathrm{Cmax}(\mathrm{ng} / \mathrm{ml})$ & $31.98 \pm 8.98$ & $260.11 \pm 46.59$ & $162.10 \pm 65.97$ & $106.01 \pm 37.79^{\mathrm{b}}$ \\
$\mathrm{AUC}_{0-\mathrm{t}}(\mathrm{hr} \cdot \mathrm{ng} / \mathrm{ml})$ & $244.44 \pm 85.90$ & $271.99 \pm 56.50$ & $169.01 \pm 66.94$ & $119.45 \pm 33.45^{\mathrm{a}}$ \\
$\mathrm{AUC}_{0 \text {-inf }}(\mathrm{hr} \cdot \mathrm{ng} / \mathrm{ml})$ & $258.74 \pm 81.02$ & $4.98 \pm 1.20$ & $4.50 \pm 1.28$ & $3.13 \pm 1.23$ \\
$\mathrm{t}_{1 / 2}(\mathrm{hr})$ & $4.44 \pm 0.98$ & $7.10 \pm 1.32$ & $5.84 \pm 1.16$ & $4.83 \pm 0.91^{\mathrm{b}}$ \\
$\mathrm{MRT}_{\text {inf }}(\mathrm{hr})$ & $6.15 \pm 0.63$ & &
\end{tabular}

Values are expressed as mean \pm S.D. of five rats. $\mathrm{BH}=$ Blue honeysuckle (fruit parts of Lonicera caerulea L., Caprifoliaceae) concentrated and lyophilized powder. Cmax: The peak plasma concentration; Tmax: Time to reach $\mathrm{Cmax}_{\mathrm{A}} \mathrm{AUC}_{0-\mathrm{t}}$ : The total area under the plasma

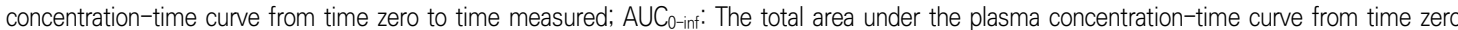
to time infinity; $\mathrm{t}_{1 / 2}$ : Half life; MRT inf: Mean residence to time infinity. ${ }^{a} p<0.01$ and ${ }^{b} p<0.05$ as compared with tamoxifen single formula administered rats. 


\section{Changes on the AUC of tamoxifen}

The $\mathrm{AUC}_{0-\mathrm{t}}$ of tamoxifen were non-significantly changed as 6.41 and $-33.69 \%$ points in tamoxifen and $\mathrm{BH} 40$ or $20 \mathrm{mg} / \mathrm{ml}$ mixed formula treated rats as compared with tamoxifen single formula treated rats, respectively. They were detected as $260.11 \pm 46.59$ and $162.10 \pm 65.97 \mathrm{hr} \cdot \mathrm{ng} / \mathrm{ml}$ in tamoxifen and BH 40 or $20 \mathrm{mg} / \mathrm{ml}$ mixed formula treated rats, and as $244.44 \pm 85.90 \mathrm{hr} \cdot \mathrm{ng} / \mathrm{ml}$ in tamoxifen single formula treated rats, respectively. However, the $\mathrm{AUC}_{0-\mathrm{t}}$ of tamoxifen was significantly $(\mathrm{p}<0.05)$ decreased as $-56.63 \%$ points in tamoxifen and $\mathrm{BH} 10 \mathrm{mg} / \mathrm{ml}$ mixed formula treated rats $(106.01 \pm 37.79 \mathrm{hr} \cdot \mathrm{ng} / \mathrm{ml}) \quad$ as compared with tamoxifen single formula treated rats, in this experiment. In addition, the $\mathrm{AUC}_{0 \text {-inf }}$ of tamoxifen were non-significantly changed as 5.12 and $-34.68 \%$ points in tamoxifen and $\mathrm{BH} 40$ or 20 $\mathrm{mg} / \mathrm{ml}$ mixed formula treated rats as compared with tamoxifen single formula treated rats, respectively. They were detected as $271.99 \pm 56.50$ and $169.01 \pm 66.94 \mathrm{hr} \cdot \mathrm{ng} / \mathrm{ml}$ in tamoxifen and $\mathrm{BH}$ 40 or $20 \mathrm{mg} / \mathrm{ml}$ mixed formula treated rats, and as $258.74 \pm 81.02 \mathrm{hr} \cdot \mathrm{ng} / \mathrm{ml}$ in tamoxifen single formula treated rats, respectively. However, the $\mathrm{AUC}_{0 \text {-inf }}$ of tamoxifen was significantly $(\mathrm{p}<0.01)$ decreased as $-53.83 \%$ points in tamoxifen and $\mathrm{BH}$ $10 \mathrm{mg} / \mathrm{ml}$ mixed formula treated rats $(119.45 \pm$ $33.45 \mathrm{hr} \cdot \mathrm{ng} / \mathrm{ml}$ ) as compared with tamoxifen single formula treated rats, in the current result (Table 1).

\section{Changes on the $t_{1 / 2}$ of tamoxifen}

The $\mathrm{t}_{1 / 2}$ of tamoxifen were non-significantly changed as $12.31,1.32$ and $-29.50 \%$ points in tamoxifen and all three different concentrations of BH mixed formula treated rats as compared with tamoxifen single formula treated rats, respectively.
They were detected as $4.98 \pm 1.20,4.50 \pm 1.28$ and $3.13 \pm 1.23 \mathrm{hr}$ in tamoxifen and $\mathrm{BH} 40,20$ or 10 $\mathrm{mg} / \mathrm{ml}$ mixed formula treated rats, and as $4.44 \pm 0.98 \mathrm{hr}$ in tamoxifen single formula treated rats, in our experiment (Table 1).

\section{Changes on the MRT inf of tamoxifen}

The $\mathrm{MRT}_{\text {inf }}$ of tamoxifen were significantly $(p<0.05)$ decreased as $-21.43 \%$ points in tamoxifen and $\mathrm{BH} 10 \mathrm{mg} / \mathrm{ml}$ mixed formula treated rats $(4.83 \pm 0.91 \mathrm{hr})$ as compared with tamoxifen single formula treated rats $(6.15 \pm 0.63 \mathrm{hr})$. The $\mathrm{MRT}_{\text {inf }}$ of tamoxifen were non-significantly changed as 15.40 and $-5.00 \%$ points in tamoxifen and $\mathrm{BH} 40$ or 20 $\mathrm{mg} / \mathrm{ml}$ mixed formula treated rats as compared with tamoxifen single formula treated rats; they were detected as $7.10 \pm 1.32$ and $5.84 \pm 1.16 \mathrm{hr}$ in tamoxifen and BH 40 or $10 \mathrm{mg} / \mathrm{ml}$ mixed formula treated rats, in this study (Table 1).

\section{Discussion}

Although single oral administration of mixed formulas consisted of tamoxifen and BH $40 \mathrm{mg} / \mathrm{ml}$ did not induced any significant changed on the plasma tamoxifen concentrations, but significant decreases of plasma tamoxifen concentrations were demonstrated in tamoxifen and $\mathrm{BH} 20 \mathrm{mg} / \mathrm{ml}$ mixed formula treated rats at 1,2 and $6 \mathrm{hr}$ after administration, and also in $\mathrm{BH} 10 \mathrm{mg} / \mathrm{ml} \mathrm{mixed}$ formula treated rats from 2 to $8 \mathrm{hr}$ after end of treatment as compared with tamoxifen $0.4 \mathrm{mg} / \mathrm{ml}$ single formula treated rats, respectively. In addition, significant increases of Tmax in tamoxifen and BH $40 \mathrm{mg} / \mathrm{ml} \mathrm{mixed} \mathrm{formula} \mathrm{treated} \mathrm{rats,} \mathrm{significant}$ decreases of Cmax in tamoxifen and BH $20 \mathrm{mg} / \mathrm{ml}$ mixed formula treated rats, and significant decreases of $\mathrm{AUC}_{0-\mathrm{t}}, \mathrm{AUC}_{0 \text {-inf }}$ and $\mathrm{MRT}_{\mathrm{inf}}$ in tamoxifen and 
BH $10 \mathrm{mg} / \mathrm{ml} \mathrm{mixed} \mathrm{formula} \mathrm{treated} \mathrm{rats} \mathrm{were}$ demonstrated as compared with tamoxifen 0.4 $\mathrm{mg} / \mathrm{ml}$ single formula treated rats, respectively. These findings are considered as direct evidences that single oral administration of mixed formulation with $\mathrm{BH} 10 \mathrm{mg} / \mathrm{ml}$ concentration significantly decreased the oral bioavailability of tamoxifen through decrease of the absorptions, but not in tamoxifen and $\mathrm{BH} 40$ and $20 \mathrm{mg} / \mathrm{ml}$ mixed formulas, suggesting formulated $\mathrm{BH}$ concentration -independencies in the current study. It, therefore, seems to be need that pharmacokinetic study after repeated administration of mixed formulas for considerable periods should be tested to conclude the effects of mixed formulation with $\mathrm{BH}$ on the pharmacokinetics of tamoxifen, and can be used as potent comprehensive and integrative medicine for the mammary cancer.

Tamoxifen was absorbed slowly following oral administration and Tmax of tamoxifen occur about 3-6 hr after a single dose $\mathrm{e}^{6,61)}$ but it rapidly and extensively metabolized in the liver, through a substrate of CYP3A, 2C9, 2D626 including an active major metabolite, N-desmethyltamoxifen has biologic activity similar to that of the parent drug $^{60,61)}$. Steady-state concentrations of tamoxifen are attained after 3-4 weeks and those of $\mathrm{N}$-desmethyltamoxifen, an active metabolite, are attained after 3-8 weeks ${ }^{62}$. Tamoxifen excreted principally in feces as polar conjugates ${ }^{63)}$ with about 5-7 days of $t_{1 / 2}$ in tamoxifen and 9-14 days in $\mathrm{N}$-desmethyltamoxifen ${ }^{59)}$. Clearance of tamoxifen is higher in female children 2-10 years of age than in women ${ }^{64,65)}$. In the present study, Tmax of tamoxifen in tamoxifen $0.4 \mathrm{mg} / \mathrm{ml}$ single formula oral treated rats was detected as $1.10 \pm 0.55 \mathrm{hr}$, and Cmax, $\mathrm{AUC}_{0-\mathrm{t}}, \mathrm{AUC}_{0 \text {-inf, }} \mathrm{t}_{1 / 2}$ and $\mathrm{MRT}_{\text {inf }}$ were detected as $31.98 \pm 8.98 \mathrm{ng} / \mathrm{ml}, 244.44 \pm 85.90 \mathrm{hr}$. $\mathrm{ng} / \mathrm{ml}, 258.74 \pm 81.02 \mathrm{hr} \cdot \mathrm{ng} / \mathrm{ml}, 4.44 \pm 0.98 \mathrm{hr}$ and $6.15 \pm 0.63 \mathrm{hr}$, respectively. In tamoxifen and $\mathrm{BH}$ $40 \mathrm{mg} / \mathrm{ml}$ mixed formula administrated rats, Tmax, Cmax, $\mathrm{AUC}_{0-\mathrm{t}}, \mathrm{AUC}_{0 \text {-inf, }} \mathrm{t}_{1 / 2}$ and $\mathrm{MRT}_{\text {inf }}$ of tamoxifen were detected as $3.00 \pm 1.00 \mathrm{hr}, 27.14 \pm 7.24 \mathrm{ng} / \mathrm{ml}$, $260.11 \pm 46.59 \mathrm{hr} \cdot \mathrm{ng} / \mathrm{ml}, 271.99 \pm 56.50 \mathrm{hr} \cdot \mathrm{ng} / \mathrm{ml}$, $4.98 \pm 1.20 \mathrm{hr}$ and $7.10 \pm 1.32 \mathrm{hr}$ as changed as 172.73, -15.13, 6.41, 5.12, 12.31 and $15.40 \%$ points as compared with tamoxifen $0.4 \mathrm{mg} / \mathrm{ml}$ single formula treated rats, in the present study. They showed significant $(\mathrm{p}<0.05)$ decreases of Tmax, but not in $\mathrm{AUC}_{0-\mathrm{t}}$ and $\mathrm{AUC}_{0 \text {-inf }}$ as compared with tamoxifen $0.4 \mathrm{mg} / \mathrm{ml}$ single formula treated rats, respectively. In addition, tamoxifen and BH $20 \mathrm{mg} / \mathrm{ml}$ mixed formula administrated rats also showed significant $(0<0.01)$ reduced of Cmax, but not in $\mathrm{AUC}_{0-\mathrm{t}}$ and $\mathrm{AUC}_{0 \text {-inf }}$ as compared with tamoxifen $0.4 \mathrm{mg} / \mathrm{ml}$ single formula treated rats, respectively. They showed 27.27, -32.90, -33.69, -34.68, 1.32 and $-5.00 \%$ points of Tmax, Cmax, $\mathrm{AUC}_{0-\mathrm{t}}, \mathrm{AUC}_{0-\mathrm{inf}}, \mathrm{t}_{1 / 2}$ and $\mathrm{MRT}_{\text {inf }}$ as compared with tamoxifen $0.4 \mathrm{mg} / \mathrm{ml}$ single formula treated rats, and detetced as $1.40 \pm 0.89 \mathrm{hr}, 21.46 \pm 4.01 \mathrm{ng} / \mathrm{ml}, 162.10 \pm 65.97 \mathrm{hr}$. $\mathrm{ng} / \mathrm{ml}, 169.01 \pm 66.94 \mathrm{hr} \cdot \mathrm{ng} / \mathrm{ml}, 4.50 \pm 1.28 \mathrm{hr}$ and $5.84 \pm 1.16 \mathrm{hr} \mathrm{hr}$, in our result. However, Tmax, Cmax, $\quad \mathrm{AUC}_{0-\mathrm{t}}, \quad \mathrm{AUC}_{0 \text {-inf }}, \mathrm{t}_{1 / 2}$ and $\mathrm{MRT}_{\mathrm{inf}}$ of tamoxifen in tamoxifen and $\mathrm{BH} 10 \mathrm{mg} / \mathrm{ml}$ mixed formula administrated rats were detected as $1.20 \pm 0.45 \mathrm{hr}, 21.18 \pm 7.61 \mathrm{ng} / \mathrm{ml}, 106.01 \pm 37.79 \mathrm{hr}$ $\cdot \mathrm{ng} / \mathrm{ml}, 119.45 \pm 33.45 \mathrm{hr} \cdot \mathrm{ng} / \mathrm{ml}, 3.13 \pm 1.23 \mathrm{hr}$ and $4.83 \pm 0.91 \mathrm{hr}$ as changed as 9.09, $-33.77,-56.63$, $-53.83,-29.50$ and $-21.43 \%$ points as compared with tamoxifen $0.4 \mathrm{mg} / \mathrm{ml}$ single formula treated rats; They showed significant $(\mathrm{p}<0.01$ or $\mathrm{p}<0.05$ ) decreases of $\mathrm{AUC}_{0-\mathrm{t}}, \mathrm{AUC}_{0 \text {-inf }}$ and $\mathrm{MRT}_{\text {inf }}$ as compared with tamoxifen $0.4 \mathrm{mg} / \mathrm{ml}$ single formula treated rats, in the current study. 
Tamoxifen rapidly and extensively metabolized in the liver, through a substrate of CYP3A, 2C9, 2D626 to active major metabolite, N-desmethyltamoxifen ${ }^{6,61)}$ and, therefore, tamoxifen can be interacted with various drugs ${ }^{29-36)}$. In addition the possibilities that tamoxifen competitively interacted with cyclosporine, erythromycin, diltiazem, erythromycin and nifedipine were also suggested in vitro experiments ${ }^{37-39)}$. The severities of various side effects arise from tamoxifen treatment, especially bone $\operatorname{loss}^{10}$, endometrial cancer $^{11)}$, thromboembolism ${ }^{12)}$, fatty liver $^{13)}$, reduced cognition ${ }^{14)}$, semantic memory scores $^{15)}$ and libido ${ }^{16,17)}$, premature growth plate fusion $^{18)}$, immune suppression ${ }^{19,20)}$ and hypersensitivity $^{21,22)}$ are considered as directly co-related with absorption and excretion of tamoxifen or pharmacodynamics. In the present study, it is demonstrated that single oral administration of mixed formulation with $\mathrm{BH} 10$ $\mathrm{mg} / \mathrm{ml}$ concentration significantly decreased the oral bioavailability of tamoxifen through decrease of the absorptions, but not in tamoxifen and $\mathrm{BH}$ 40 and $20 \mathrm{mg} / \mathrm{ml}$ mixed formulas, suggesting formulated $\mathrm{BH}$ concentration-independencies and repeated administration of mixed formulas for considerable periods seems to be need to conclude the effects of mixed formulation with $\mathrm{BH}$ on the pharmacokinetics of tamoxifen and whether can be adjusted to mammary cancer patient as potent comprehensive and integrative medicine, at least in a condition of this experiment.

\section{Conclusions}

Taken together, single oral administration of tamoxifen $0.4 \mathrm{mg} / \mathrm{ml}$ and $\mathrm{BH} 10 \mathrm{mg} / \mathrm{ml}$ mixed formulation induced significant decrease of the oral bioavailability of tamoxifen through inhibition of absorptions. However, tamoxifen $0.4 \mathrm{mg} / \mathrm{ml}$ and BH 40 or $20 \mathrm{mg} / \mathrm{ml}$ mixed formulation did not critically influenced on the oral bioavailability (AUCs) of tamoxifen, suggesting formulated $\mathrm{BH}$ concentration-independencies. It, therefore, seems to be need that pharmacokinetic study after repeated administration of mixed formulas for considerable periods should be tested to conclude the effects of mixed formulation with $\mathrm{BH}$ on the pharmacokinetics of tamoxifen. It can be used as potent comprehensive and integrative medicine for the mammary cancer.

\section{Acknowledgments}

This work was supported by the National Research Foundation of Korea(NRF) grant funded by the Korea government(MSIT) (No.2018R1A5A 2025272), and by grant of Korea of Health \& Welfare, Republic of Korea (Project No: 20-11-0090-091-3000-3033-320).

\section{References}

1. Ruiz-Garcia A, Bermejo M, Moss A, Casabo VG, Pharmacokinetics in drug discovery. Journal of pharmaceutical sciences, 2008;97(2): 654-90.

2. Kang SB, Shon HS, Park SJ, Song $\mathrm{CH}, \mathrm{Ku}$ SK, Effects of Chungsinoryungsan, a polyherbal complex, on the pharmacokinetic profiles of perindopril in rats. Biomedical reports, 2014; 2(6):855-60.

3. Baek KM, Kwon OD, Kim HS, Park SJ, Song $\mathrm{CH}, \mathrm{Ku} \mathrm{SK}$, Pharmacokinetic Profiles of Donepezil in Combination with Gwibi -Chongmyungtang in Rats. Int J Pharmacol, 2015;11(4):343-50.

4. Kim DJ, Ryu HM, Park Si, Park SJ, Song 
$\mathrm{CH}, \mathrm{Ku} \mathrm{SK}$, Pharmacokinetic properties of ondansetron in combination with ijintang -gamibang, polyherbal complex in rats. Int $\mathrm{J}$ Pharmacol, 2015;11:351-8.

5. BIG 1-98 Collaborative Group, Mouridsen H, Giobbie-Hurder A, Goldhirsch A, Thurlimann B, Paridaens R, et al., Letrozole therapy alone or in sequence with tamoxifen in women with breast cancer. The New England journal of medicine, 2009;361(8):766-76.

6. Jordan VC, Fourteenth Gaddum Memorial Lecture. A current view of tamoxifen for the treatment and prevention of breast cancer. British journal of pharmacology, 1993;110(2): 507-17.

7. Jordan VC, Tamoxifen (ICI46,474) as a targeted therapy to treat and prevent breast cancer. British journal of pharmacology, 2006;147 Suppl 1:S269-76.

8. Massarweh S, Osborne CK, Creighton CJ, Qin L, Tsimelzon A, Huang S, et al., Tamoxifen resistance in breast tumors is driven by growth factor receptor signaling with repression of classic estrogen receptor genomic function. Cancer research, 2008;68(3): 826-33.

9. Hurtado A, Holmes KA, Geistlinger TR, Hutcheson IR, Nicholson RI, Brown M, et al., Regulation of ERBB2 by oestrogen receptor -PAX2 determines response to tamoxifen. Nature, 2008;456(7222):663-6.

10. Vehmanen L, Elomaa I, Blomqvist C, Saarto T, Tamoxifen treatment after adjuvant chemotherapy has opposite effects on bone mineral density in premenopausal patients depending on menstrual status. Journal of clinical oncology : official journal of the American Society of Clinical Oncology, 2006;24(4):675-80.

11. Grilli S, Tamoxifen (TAM): the dispute goes on. Annali dell'Istituto superiore di sanita, 2006;42(2):170-3.

12. Decensi A, Maisonneuve P, Rotmensz N, Bettega D, Costa A, Sacchini V, et al., Effect of tamoxifen on venous thromboembolic events in a breast cancer prevention trial. Circulation, 2005;111(5):650-6.

13. Osman KA, Osman MM, Ahmed MH, Tamoxifen -induced non-alcoholic steatohepatitis: where are we now and where are we going? Expert opinion on drug safety, 2007;6(1):1-4.

14. Paganini-Hill A, Clark LJ, Preliminary assessment of cognitive function in breast cancer patients treated with tamoxifen. Breast cancer research and treatment, 2000;64(2): 165-76.

15. Eberling JL, Wu C, Tong-Turnbeaugh $\mathrm{R}$, Jagust WJ, Estrogen- and tamoxifen-associated effects on brain structure and function. NeuroImage, 2004;21(1):364-71.

16. Mortimer JE, Boucher L, Baty J, Knapp DL, Ryan E, Rowland JH, Effect of tamoxifen on sexual functioning in patients with breast cancer. Journal of clinical oncology : official journal of the American Society of Clinical Oncology, 1999;17(5):1488-92.

17. Cella D, Fallowfield L, Barker P, Cuzick J, Locker G, Howell A, et al., Quality of life of postmenopausal women in the ATAC ("Arimidex", tamoxifen, alone or in combination) trial after completion of 5 years' adjuvant treatment for early breast cancer. Breast cancer research and treatment, 2006; 100(3):273-84.

18. Karimian E, Chagin AS, Gjerde J, Heino T, Lien EA, Ohlsson C, et al., Tamoxifen impairs both longitudinal and cortical bone growth in young male rats. Journal of bone and mineral 
research : the official journal of the American Society for Bone and Mineral Research, 2008;23(8):1267-77.

19. Wilson SC, Knight PG, Cunningham FJ, Evidence for the involvement of central conversion of testosterone to oestradiol-17 beta in the regulation of luteinizing hormone secretion in the cockerel. The Journal of endocrinology, 1983;99(2):301-10.

20. Nalbandian G, Paharkova-Vatchkova V, Mao A, Nale S, Kovats S, The selective estrogen receptor modulators, tamoxifen and raloxifene, impair dendritic cell differentiation and activation. Journal of immunology (Baltimore, Md. : 1950), 2005;175(4):2666-75.

21. Berstein LM, Wang JP, Zheng H, Yue W, Conaway M, Santen RJ, Long-term exposure to tamoxifen induces hypersensitivity to estradiol. Clinical cancer research : an official journal of the American Association for Cancer Research, 2004;10(4):1530-4.

22. Rousset-Jablonski C, Thalabard JC, Gompel A, Tamoxifen contraindicated in women with hereditary angioedema? Annals of oncology : official journal of the European Society for Medical Oncology, 2009;20(7):1281-2.

23. Fisher B, Costantino JP, Wickerham DL, Redmond CK, Kavanah M, Cronin WM, et al., Tamoxifen for prevention of breast cancer: report of the National Surgical Adjuvant Breast and Bowel Project P-1 Study. Journal of the National Cancer Institute, 1998;90(18): 1371-88.

24. Pienta KJ, Redman BG, Esper PS, Flaherty LE, A phase II evaluation of oral tamoxifen and intermittent intravenous vinblastine in hormone-refractory adenocarcinoma of the prostate. American journal of clinical oncology,
1996;19(5):500-3.

25. Zeneca Pharmaceuticals, Nolvadex (tamoxifen citrate) prescribing information. 1998.

26. Braems G, Denys H, De Wever O, Cocquyt V, Van den Broecke R, Use of tamoxifen before and during pregnancy. The oncologist, 2011; 16(11):1547-51.

27. Karn A, Jha AK, Shrestha S, Acharya B, Poudel S, Bhandari RB, Tamoxifen for breast cancer. JNMA; journal of the Nepal Medical Association, 2010;49(177):62-7.

28. Notley LM, Crewe KH, Taylor PJ, Lennard MS, Gillam EM, Characterization of the human cytochrome P450 forms involved in metabolism of tamoxifen to its alpha-hydroxy and alpha,4-dihydroxy derivatives. Chemical research in toxicology, 2005;18(10):1611-8.

29. Lien EA, Anker G, Lonning PE, Solheim E, Ueland PM, Decreased serum concentrations of tamoxifen and its metabolites induced by aminoglutethimide. Cancer research, 1990;50(18): 5851-7.

30. Ritchie LD, Grant SM, Tamoxifen-warfarin interaction: the Aberdeen hospitals drug file. BMJ, 1989;298(6682):1253.

31. Tenni P, Lalich DL, Byrne MJ, Life threatening interaction between tamoxifen and warfarin. BMJ, 1989;298(6666):93.

32. Lamberts SW, Verleun T, Hofland L, Oosterom R, Differences in the interaction between dopamine and estradiol on prolactin release by cultured normal and tumorous human pituitary cells. The Journal of clinical endocrinology and metabolism, 1986;63(6): $1342-7$

33. Dowsett M, Pfister C, Johnston SR, Miles DW, Houston SJ, Verbeek JA, et al., Impact of tamoxifen on the pharmacokinetics and 
endocrine effects of the aromatase inhibitor letrozole in postmenopausal women with breast cancer. Clinical cancer research : an official journal of the American Association for Cancer Research, 1999;5(9):2338-43.

34. Reid AD, Horobin JM, Newman EL, Preece PE, Tamoxifen metabolism is altered by simultaneous administration of medroxyproge -sterone acetate in breast cancer patients. Breast cancer research and treatment, 1992; 22(2): 153-6.

35. Dehal SS, Brodie AM, Kupfer D, The aromatase inactivator 4-hydroxyandrostenedione (4-OH-A) inhibits tamoxifen metabolism by rat hepatic cytochrome P-450 3A: potential for drug-drug interaction of tamoxifen and 4-OH-A in combined anti-breast cancer therapy. Drug metabolism and disposition: the biological fate of chemicals, 1999;27(3): 389-94.

36. West CM, Reeves SJ, Brough W, Additive interaction between tamoxifen and rifampicin in human biliary tract carcinoma cells. Cancer letters, 1990;55(2):159-63.

37. Mani C, Gelboin HV, Park SS, Pearce R, Parkinson A, Kupfer D, Metabolism of the antimammary cancer antiestrogenic agent tamoxifen. I. Cytochrome P-450-catalyzed $\mathrm{N}$-demethylation and 4-hydroxylation. Drug metabolism and disposition: the biological fate of chemicals, 1993;21(4):645-56.

38. Mani C, Pearce R, Parkinson A, Kupfer D, Involvement of cytochrome P4503A in catalysis of tamoxifen activation and covalent binding to rat and human liver microsomes. Carcinogenesis, 1994;15(12):2715-20.

39. Williams JA, Ring BJ, Cantrell VE, Jones DR, Eckstein J, Ruterbories K, et al., Comparative metabolic capabilities of CYP3A4, CYP3A5, and CYP3A7. Drug metabolism and disposition: the biological fate of chemicals, 2002;30(8): 883-91.

40. Kwak MA, Park SJ, Park SH, Lee YJ, Ku SK, Effect of Jaeumkanghwatang (JEKHT), a Polyherbal Formula on the Pharmacokinetics Profiles of Tamoxifen in Male SD Rats (1)Single Oral Combination Treatment of Tamoxifen $50 \mathrm{mg} / \mathrm{kg}$ with JEKHT $100 \mathrm{mg} / \mathrm{kg}$ within 5 min -. J Korean Med, 2016;37(2): $1-11$.

41. Park SJ, Kwak MA, Park SH, Lee YJ, Ku SK, Effect of Jaeumkanghwatang (JEKHT), a Polyherbal Formula on the Pharmacokinetics Profiles of Tamoxifen in Male SD Rats (2) Oral Combination Treatment of Tamoxifen 50 $\mathrm{mg} / \mathrm{kg}$ with JEKHT $100 \mathrm{mg} / \mathrm{kg}$ on JEKHT 6-day Repeated Pretreated Rats with 8-day Repeated Co-administration -. J Soc Preventive Korean Med, 2016;20(2):97-109.

42. Ryu EA, Kang SJ, Song CH, Lee BH, Choi $\mathrm{SH}$, Han $\mathrm{CH}$, et al., Effect of Gamiondam-tang (GMODT), a Polyherbal Formula on the Pharmacokinetics Profiles of Tamoxifen in Male SD Rats J Korean Med, 2017;38(2): 61-72.

43. Ryu EA, Kang SJ, Song $\mathrm{CH}$, Lee BH, Choi $\mathrm{SH}$, Han $\mathrm{CH}$, et al., Effect of Gamiondam-tang (GMODT), a Polyherbal Formula on the Pharmacokinetics Profiles of Tamoxifen in Male SD Rats (2) - Single Oral Combination Treatment of Tamoxifen $50 \mathrm{mg} / \mathrm{kg}$ with GMODT $100 \mathrm{mg} / \mathrm{kg}$ with $2.5 \mathrm{hr}$-intervals -. Journal of Society of Preventive Korean Medicine, 2017;21(2):127-37.

44. Svarcova I, Heinrich J, Valentova K, Berry fruits as a source of biologically active 
compounds: the case of Lonicera caerulea. Biomedical papers of the Medical Faculty of the University Palacky, Olomouc, Czechoslovakia, 2007;151(2):163-74.

45. Zhao $H$, Wang $Z$, Ma F, Yang $X$, Cheng $C$, Yao L, Protective effect of anthocyanin from Lonicera Caerulea var. Edulis on radiation -induced damage in mice. International journal of molecular sciences, 2012;13(9):11773-82.

46. Jurgoński A, Juśkiewicz J, Zduńczyk Z, An anthocyanin-rich extract from Kamchatka honeysuckle increases enzymatic activity within the gut and ameliorates abnormal lipid and glucose metabolism in rats. Nutrition, 2013;29(6):898-902.

47. Palíková I, Valentová K, Oborná I, Ulrichová $\mathrm{J}$, Protectivity of blue honeysuckle extract against oxidative human endothelial cells and rat hepatocyte damage. Journal of agricultural and food chemistry, 2009;57(15):6584-9.

48. Jin XH, Ohgami K, Shiratori K, Suzuki Y, Koyama Y, Yoshida K, et al., Effects of blue honeysuckle (Lonicera caerulea L.) extract on lipopolysaccharide-induced inflammation in vitro and in vivo. Experimental eye research, 2006;82(5):860-7.

49. Chen L, Xin X, Yuan Q, Su D, Liu W, Phytochemical properties and antioxidant capacities of various colored berries. Journal of the science of food and agriculture, 2014;94(2):180-8.

50. Vostálová J, Galandáková A, Paliková I, Ulrichová J, Doležal D, Lichnovská R, et al., Lonicera caerulea fruits reduce UVA-induced damage in hairless mice. Journal of photochemistry and photobiology. B, Biology, 2013;128:1-11.

51. Kim HS, Park SI, Choi SH, Song CH, Park
SJ, Shin YK, et al., Single oral dose toxicity test of blue honeysuckle concentrate in mice. Toxicological research, 2015;31(1):61-8.

52. AOAC (Association of Official Analytical Chemists), Official Methods of Analysis International. 17th ed. AOAC. 2000.

53. Singleton VL, Timberlake CF, Lea AGH, The phenolic cinnamates of white grapes and wine. Journal of the science of food and agriculture, 1978;29(4):403-10.

54. Yang J, Meyers KJ, van der Heide J, Liu RH, Varietal differences in phenolic content and antioxidant and antiproliferative activities of onions. Journal of agricultural and food chemistry, 2004;52(22):6787-93.

55. Boyles MJ, Wrolstad RE, Anthocyanin Composition of Red Raspberry Juice: Influences of Cultivar, Processing, and Environmental Factors. J Food Sci, 1993;58(5): 1135-41.

56. Bailer AJ, Testing for the equality of area under the curves when using destructive measurement techniques. Journal of pharmacokinetics and biopharmaceutics, 1988;16(3):303-9.

57. Chiou WL, Critical evaluation of the potential error in pharmacokinetic studies of using the linear trapezoidal rule method for the calculation of the area under the plasma level-time curve. Journal of pharmacokinetics and biopharmaceutics, 1978;6(6):539-46.

58. Kang SJ, Lee JE, Lee EK, Jung DH, Song $\mathrm{CH}$, Park SJ, et al., Fermentation with Aquilariae Lignum enhances the anti-diabetic activity of green tea in type II diabetic $\mathrm{db} / \mathrm{db}$ mouse. Nutrients, 2014;6(9):3536-71.

59. Adam HK, Patterson JS, Kemp JV, Studies on the metabolism and pharmacokinetics of 
tamoxifen in normal volunteers. Cancer treatment reports, 1980;64(6-7):761-4.

60. Fabian C, Sternson L, Barnett M, Clinical pharmacology of tamoxifen in patients with breast cancer: comparison of traditional and loading dose schedules. Cancer treatment reports, 1980;64(6-7):765-73.

61. Murphy C, Fotsis T, Pantzar P, Adlercreutz H, Martin F, Analysis of tamoxifen and its metabolites in human plasma by gas chromatography-mass spectrometry (GC-MS) using selected ion monitoring (SIM). Journal of steroid biochemistry, 1987;26(5):547-55.

62. Jordan VC, Metabolites of tamoxifen in animals and man: identification, pharmacology, and significance. Breast cancer research and treatment, 1982;2(2):123-38.

63. Sun D, Sharma AK, Dellinger RW, Blevins -Primeau AS, Balliet RM, Chen G, et al., Glucuronidation of active tamoxifen metabolites by the human UDP glucuronosyltransferases.
Drug metabolism and disposition: the biological fate of chemicals, 2007;35(11): 2006-14.

64. AstraZeneca Pharmaceuticals, Nolvadex (tamoxifen citrate) prescribing information. 2003.

65. Hall WA, Doolittle ND, Daman M, Bruns PK, Muldoon L, Fortin D, et al., Osmotic blood-brain barrier disruption chemotherapy for diffuse pontine gliomas. Journal of neuro-oncology, 2006;77(3):279-84.

\section{ORCID}

Jin-Ryul Hu https://orcid.org/0000-0003-3953-4010

Tae-Woo Jang https://orcid.org/0000-0003-2014-9817

Su-Jin Kang https://orcid.org/0000-0002-1197-8253

Sae-Kwang Ku https://orcid.org/0000-0003-1269-3804

Seong-Hun Choi https://orcid.org/0000-0002-5942-1550

Young-Joon Lee https://orcid.org/0000-0001-6439-9987 